\title{
Preparation and in vitro characterization of scaffolds of poly(L-lactic acid) containing bioactive glass ceramic nanoparticles
}

\author{
Zhongkui Hong, Rui L. Reis, João F. Mano* \\ University of Minho, 3B́s Research Group - Biomaterials, Biodegradables and Biomimetics, Department of Polymer Engineering, \\ Campus de Gualtar, 4710-057 Braga, Portugal \\ $I B B$ - Institute for Biotechnology and Bioengineering, Braga, Portugal
}

Received 30 November 2007; received in revised form 4 March 2008; accepted 20 March 2008

Available online 1 April 2008

\begin{abstract}
Porous nanocomposite scaffolds of poly(L-lactic acid) (PLLA) containing different quantities of bioactive glass ceramic (BGC) nanoparticles $\left(\mathrm{SiO}_{2}: \mathrm{CaO}: \mathrm{P}_{2} \mathrm{O}_{5} \approx 55: 40: 5(\mathrm{~mol})\right)$ were prepared by a thermally induced phase-separation method. Dioxane was used as the solvent for PLLA. Introduction of less than $20 \mathrm{wt} . \%$ of BGC nanoparticles did not remarkably affect the porosity of PLLA foam. However, as the BGC content increased to $30 \mathrm{wt} . \%$, the porosity of the composite was observed to decrease rapidly. The compressive modulus of the scaffolds increased from 5.5 to $8.0 \mathrm{MPa}$, while the compressive strength increased from 0.28 to $0.35 \mathrm{MPa}$ as the BGC content increased from 0 to $30 \mathrm{wt} . \%$. The in vitro bioactivity and biodegradability of nanocomposites were investigated by incubation in simulated body fluid (SBF) and phosphate-buffered saline, respectively. Scanning electron microscopy, energy dispersive X-ray spectroscopy, Fourier transform infrared spectroscopy and X-ray diffraction were employed to monitor the surface variation of neat PLLA and PLLA/ BGC porous scaffolds during incubation. PLLA/(20 wt.\%)BGC composite exhibited the best mineralization property in SBF, while the PLLA/(10 wt.\%)BGC composite showed the highest water absorption ability.
\end{abstract}

(C) 2008 Acta Materialia Inc. Published by Elsevier Ltd. All rights reserved.

Keywords: Nanocomposites; Poly(L-lactic acid); Bioactive glass ceramic; Bone tissue engineering; Scaffolds

\section{Introduction}

Tissue engineering has been considered as a practical therapeutic approach towards the regeneration of human tissue [1]. Biomaterials for application in tissue engineering could guide cell attachment, cell proliferation and tissue regeneration when implanted at the desired site in the patient's body. Composites of polymers and bioactive ceramics have attracted increasing attention as promising biomaterials for bone tissue engineering [2-4]. Threedimensional (3D) porous composite scaffolds can induce the ingrowth of cell to the desired shape and may facilitate the vascularization of new generated tissue $[5,6]$.

\footnotetext{
${ }^{*}$ Corresponding author. Tel.: +351 253604497/253510320.

E-mail address: jmano@dep.uminho.pt (J.F. Mano).
}

The desirable combination of biocompatibility of biodegradable polymers and the bioactivity of bioceramics could be achieved by preparation of porous polymer/ceramic composites by different methods [7-11].

Numerous biodegradable polymers have been used in the preparation of polymer/ceramic composite. These polymer included poly(L-lactic acid) (PLLA) [2,10-18], poly(caprolactone) [4,19,20], poly(glycolic acid) [21], poly(glycolide-co-lactide) [22,23], poly(caprolactone-colactide) $[24,25]$ and polysaccharides [3,26-29].

Some ceramics and glasses can directly bond to living bone without the formation of surrounding fibrous tissue. In such cases a bone-like apatite layer is deposited in vivo between the implant and bone [30]. This mineralization ability has been defined as bioactivity of biomaterial. Hydroxyapatite (HA), which constitutes the inorganic fraction of bone, has been considered to be a bioactive material 
due to its osteoconductivity [31]. However, recent investigation has revealed that bioactive glasses (BAGs) or bioactive glass ceramics (BGCs) have a much better performance in bone tissue engineering than HA [32,33]. BAG has been used as bone filler material, applied in clinical treatment of periodontal disease [34], and used to replace damaged middle ear bone [35]. Porous BAG can facilitate vascularization and new bone ingrowth, so has became a potential useful material for orthopedic applications [36-38]. Meanwhile, the bioactive filler, comprising BAG and BGC particles, can serve as a reinforcing component to enhance the stiffness of polymer composites.

Compared with micron-sized bioactive ceramic particles, nano-sized particles have a large specific surface area and can form a tighter interface with the polymer matrix in composites. Introduction of nano-sized BGC particles into polymeric materials can not only endow polymer scaffolds with biomineralization capability but also increase the stiffness of polymer material without greatly decreasing the mechanical strength [39-41]. It was found that BAG nanoparticles prepared via a three-step solgel method exhibit bioactive features when compounded with PLLA [42]. In this study, BGC nanoparticles with the composition of $\mathrm{SiO}_{2}: \mathrm{CaO}: \mathrm{P}_{2} \mathrm{O}_{5} \approx 55: 40: 5(\mathrm{~mol})$ were chosen as the bioactive filler to be combined with PLLA in order to produce a new generation of biodegradable scaffolds.

\section{Materials and methods}

\subsection{Materials}

Tetraethoxysilane (TEOS), calcium nitrate, citric acid and ammonium dibasic phosphate were obtained from Sigma. Poly(ethylene glycol) (PEG, $M_{\mathrm{n}}$ 16,000-24,000) and dioxane were purchased from Fluka. PLLA $\left(M_{\mathrm{w}}\right.$ 200,000) was obtained from Stratec.

\subsection{Preparation of the BGC nanoparticles based on $\mathrm{SiO}_{2}-\mathrm{CaO}-\mathrm{P}_{2} \mathrm{O}_{5}$}

BGC $\left(\mathrm{SiO}_{2}: \mathrm{CaO}: \mathrm{P}_{2} \mathrm{O}_{5} \approx 55: 40: 5(\mathrm{~mol})\right)$ nanoparticles were prepared in accordance with the method described in our previous publications $[42,43]$. Briefly, $7.639 \mathrm{~g}$ calcium nitrate and $9.84 \mathrm{ml}$ of TEOS were dispersed in a mixture of $120 \mathrm{ml}$ deionized water and $60 \mathrm{ml}$ ethanol. The $\mathrm{pH}$ of the solution was adjusted to 1-2 with citric acid. Once it had become transparent, this solution was dropped into $1500 \mathrm{ml}$ of deionized water containing $1.078 \mathrm{~g}$ of ammonium dibasic phosphate under vigorous stirring. During this procedure, the $\mathrm{pH}$ of the solution was kept at around 11 with continuous additions of ammonia water. After $48 \mathrm{~h}$ of stirring and $24 \mathrm{~h}$ of ageing, the precipitate was separated from the reaction mixture by centrifugation at $10,000 \mathrm{rpm}$, and washed three times with deionized water. Then, the white precipitate was suspended in a $2 \%(\mathrm{w} / \mathrm{v}) \mathrm{PEG}-$ water solution. The precipitate coated with PEG was freeze dried and calcinated at $700{ }^{\circ} \mathrm{C}$, to obtain the final white $\mathrm{BGC}$ nanoparticles.

\subsection{Transmission electron microscopy (TEM) observation}

TEM (JEOL JEM-1010) was used to observe the size and shape of the BGC nanoparticles. The TEM specimen was prepared by putting one drop of $0.1 \%$ BGC/ethanol suspension onto a TEM grid covered with carbon film and evaporating the solvent completely at room temperature.

\subsection{Preparation of the PLLA/BGC nanocomposite scaffolds}

The PLLA/BGC nanocomposites scaffolds were prepared using a freeze drying method. Briefly, a given amount of BGC powder was homogeneously suspended in dioxane using an ultrasonicator and a magnetic stirrer. PLLA was dissolved in the BGC-dioxane suspension to produce an homogeneous 5\% (w/v) PLLA-dioxane solution. The mixture was stirred overnight to obtain a polymer solution. After freeze drying at $-80^{\circ} \mathrm{C}$ for 1 week, porous PLLA/BGC composite scaffolds were obtained.

\subsection{Porosity of composite}

The total porosity of the composite with different BGC contents was calculated on the basis of their apparent density $\rho$ and bulk density $\rho_{0}$ according to the following equation: porosity $\%=\left(1-\rho / \rho_{0}\right) \times 100$. The $\rho$ and $\rho_{0}$ were measured from porous scaffold and bulk samples, respectively, on the basis of their dimensions and weights. Triplicate measurements were carried out to obtain their mean values.

\subsection{Mechanical properties}

An Instron test machine (1121 Instron Instruments, UK) was employed to evaluate the compressive properties of the porous scaffolds at room temperature. Cubic specimens $10 \times 10 \times 10 \mathrm{~mm}$ were placed between two solid platens and compressed at a rate of $1 \mathrm{~mm} \mathrm{~min}^{-1}$. The degree of statistical significance between composites and control PLLA scaffolds was estimated by $t$-test, with $P<0.05$ being taken as statistically significant. Five samples of each formulation were analyzed to determine statistical significance.

\subsection{In vitro bioactivity study}

The in vitro bioactivity test was carried out by soaking $10 \times 10 \times 2 \mathrm{~mm}$ porous scaffolds in $10 \mathrm{ml}$ of simulated body fluid (SBF; $\mathrm{Na}^{+} 142.0, \mathrm{~K}^{+} 5.0, \mathrm{Ca}^{2+} 2.5, \mathrm{Mg}^{2+} 1.5$, $\mathrm{Cl}^{-} 148.0, \mathrm{HCO}^{3-} 4.2, \mathrm{HPO}_{4}^{2-} 1.0, \mathrm{SO}_{4}^{2-} 0.5 \mathrm{mM}$ ) in conical flasks, and placing the samples in an oven at $37^{\circ} \mathrm{C}$ for 1,3 , 7, 14 and 21 days. After the different soaking periods, the scaffolds were taken out from SBF, rinsed with deionized water and freeze dried. The formation of apatite on the 
porous PLLA and PLLA/BGC composite were characterized by scanning electron microscopy (SEM), energy dispersive X-ray spectroscopy (EDX), Fourier transform infrared spectroscopy (FTIR) and X-ray diffraction (XRD).

\subsection{SEM and EDX}

SEM images of the porous morphologies and apatite formation on the scaffolds were obtained at $15 \mathrm{kV}$ on a Leica Cambridge S-360 microscope equipped with a LINK eXLII X-ray energy dispersion spectrometer. For SEM observation, samples were coated with gold using a sputter coater (JFC 1100, JEOL). For EDX analysis, all samples were coated with carbon to avoid the overlap of the peaks of gold and phosphorous $[44,45]$.

\subsection{FTIR spectroscopic analysis}

A Bio-Rad Win-IR spectrometer was employed for FTIR spectroscopic analysis. The powders scratched from the surface of a PLLA/(20 wt.\%)BGC scaffold soaked in $\mathrm{SBF}$ for 21 days were dried at $150{ }^{\circ} \mathrm{C}$ for $2 \mathrm{~h}$ under vacuum to remove adsorbed water, mixed with $\mathrm{KBr}$ powder and pressed into a disk suitable for FTIR measurement. The FTIR spectra were recorded from 400 to $4000 \mathrm{~cm}^{-1}$.

\subsection{0. $X R D$}

XRD analysis were performed on an X-ray diffractometer (Philips PW 1710, Netherlands) with $\mathrm{Cu} \mathrm{K} \alpha$ radiation $(\lambda=0.154 \mathrm{~nm})$. Voltage and current were selected as $40 \mathrm{kV}$ and $50 \mathrm{~mA}$, respectively. Data were collected from $2 \theta=10^{\circ}$ to $60^{\circ}$ with a step size of $0.02^{\circ}$.

\subsection{In vitro degradation study}

In vitro degradation studies were carried out via the same method described in previous work [42]. Briefly, samples with dimensions of $10 \times 10 \times 2 \mathrm{~mm}$ were sterilized by UV exposure under a laminar flow hood for $10 \mathrm{~min}$ on each side and placed in sterile Falcon tubes. For each time point, three samples of each composition were immersed in $10 \mathrm{ml}$ phosphate-buffered saline (PBS) and incubated under slow tangential agitation at $37^{\circ} \mathrm{C}$. The $\mathrm{pH}$ of the medium was recorded at each time point. After any given time point, samples of each composition were removed from the PBS and weighed $\left(W_{\mathrm{w}}\right)$ after wiping the surface with filter paper. Each sample was repeatedly rinsed with deionized water to remove the soluble inorganic salt, and weighed $\left(W_{\mathrm{d}}\right)$ after being completely dried in an oven. Water absorption $\left(W_{\mathrm{A}} \%\right)$ and weight loss $\left(W_{\mathrm{L}} \%\right)$ were calculated according to the following equations, respectively:

$$
\begin{aligned}
& W_{\mathrm{A}} \%=\left[\left(W_{\mathrm{w}}-W_{\mathrm{i}}\right) / W_{\mathrm{i}}\right] \times 100 \% \\
& W_{\mathrm{L}} \%=\left[\left(W_{\mathrm{d}}-W_{\mathrm{i}}\right) / W_{\mathrm{i}}\right] \times 100 \%
\end{aligned}
$$

where $W_{\mathrm{i}}$ is the initial weight of each sample.

\section{Results and discussion}

\subsection{Porous PLLA/BGC nanocomposites}

A TEM image of BGC nanoparticles dispersed in ethanol is shown in Fig. 1. It can be seen that the BGC particles are homogeneous nanospheres, $\sim 20-40 \mathrm{~nm}$ in diameter. It can also be seen that BGC nanoparticles tend to aggregate to form larger BGC clusters due to the high specific surface area and surface energy of the nanoparticles.

SEM images of neat PLLA foam and PLLA/BGC composites with different BGC contents are presented in Fig. 2. The representative morphology of a neat PLLA foam (Fig. 2A and E) shows a typical microstructure of polymeric foam prepared by thermally induced phase-separation $[2,46]$. The influence of content on the microstructure of PLLA/BGC composites was investigated by varying the $\mathrm{BGC}$ content while maintaining the PLLA concentration constant in the dioxane solutions. At $10 \mathrm{wt} . \%$ (Fig. 2B) and $20 \mathrm{wt} . \%$ (Fig. 2C) BGC content, PLLA/ BGC composites show a continuous microstructure of interconnected pores $20-400 \mu \mathrm{m}$ in diameter, which is very similar to the microporous structure of pure PLLA foam (Fig. 2A). This result suggests that, up to $20 \mathrm{wt} . \%$ content, BGC nanoparticles do not influence the mechanism of pore formation via crystallization and phase-separation of dioxane. In the high-magnification image of PLLA/ (10 wt.\%)BGC and PLLA/(20 wt.\%)BGC (Fig. 2F and $\mathrm{G})$, some micro-sized BGC aggregates could be seen on the wall of pores. If the filler loading increased to $30 \mathrm{wt} . \%$, the morphology of composite appeared to be very different from the other two scaffolds (Fig. 2D and H). In this case, the pore size ranges from 10 to $150 \mu \mathrm{m}$. This reduction in pore size could be attributed to the decrease in solvent volume relative to the total weight of PLLA and BGC nanoparticles during the preparation of the composites. Moreover, high filler contents might change

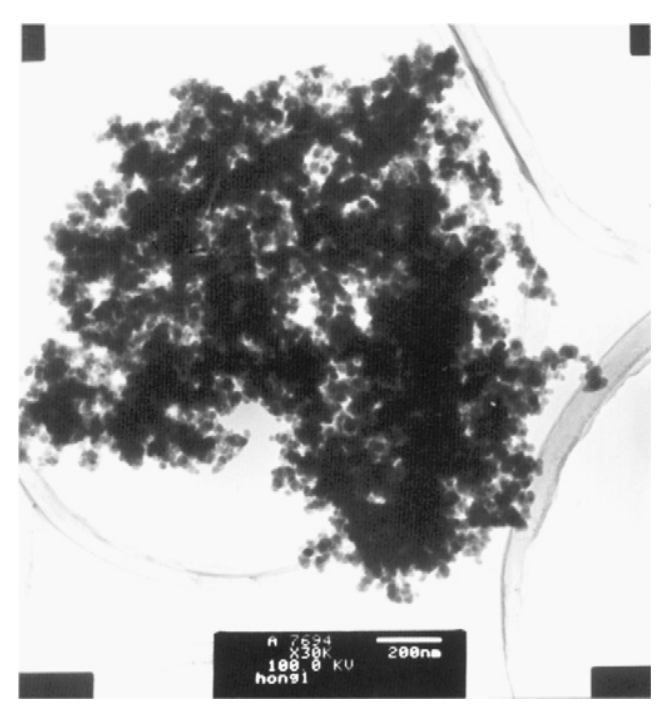

Fig. 1. TEM morphology of BGC nanoparticles. Bar is $200 \mathrm{~nm}$. 

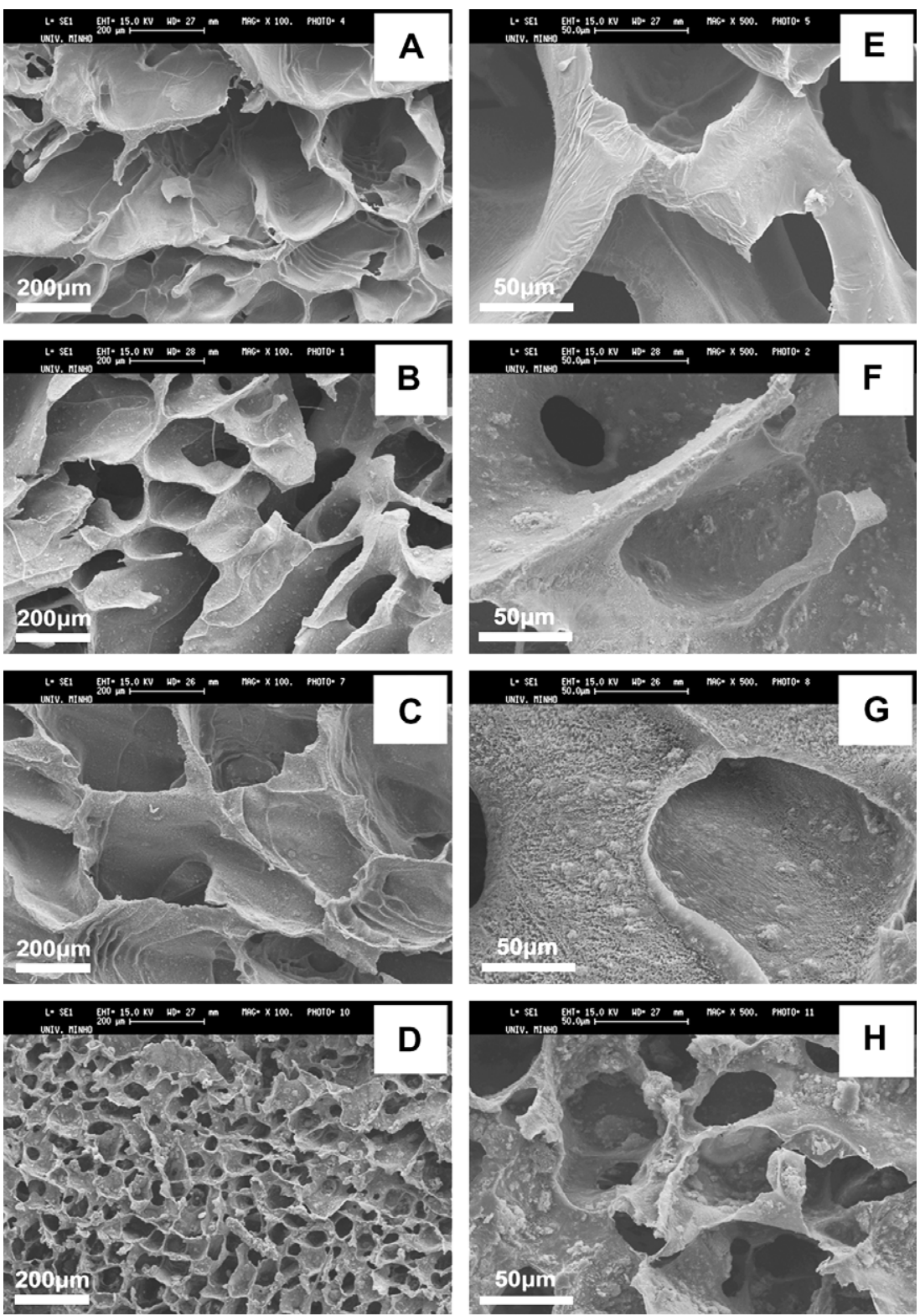

Fig. 2. SEM morphology for the porous PLLA/BGC scaffolds with different BGC contents: at low-magnification: (A) 0 wt. $\%$, (B) 10 wt. $\%$, (C) 20 wt. $\%$ and (D) $30 \mathrm{wt} . \%$; at high-magnification (E) $0 \mathrm{wt} . \%$, (F) $10 \mathrm{wt} . \%$, (G) $20 \mathrm{wt} . \%$ and (H) $30 \mathrm{wt} . \%$.

the crystallization and phase-separation behavior of dioxane solvent in the PLLA-BGC-dioxane system. The BGC nanoparticles that were densely dispersed in the PLLA-dioxane solution could provide a large number of nucleation spots and disturb the growth of the dioxane crystals at low temperature.

Both the density and porosity of the PLLA/BGC nanocomposites are listed in Table 1 . The apparent density of composite gradually increases with increasing BGC content in the scaffolds. The introduction of 10 and $20 \mathrm{wt} . \% \mathrm{BGC}$ nanoparticles in the PLLA matrix does not noticeably change the porosity of the PLLA foam. However, when the filler content increased to $30 \mathrm{wt} . \%$, the porosity of the composites apparently decreased greatly. This finding is in agreement with the result of SEM observation.
Table 1

Apparent density and porosity of the PLLA/BGC nanocomposite scaffolds

\begin{tabular}{llll}
\hline $\begin{array}{l}\text { BGC content in } \\
\begin{array}{l}\text { composite } \\
(\text { wt. } \%)\end{array}\end{array}$ & $\begin{array}{l}\text { Apparent } \\
\text { density }(\rho, \\
\left.\mathrm{g} \mathrm{cm}^{-3}\right)\end{array}$ & $\begin{array}{l}\text { Bulk density of PLLA/ } \\
\text { BGC composite }\left(\rho_{0},\right.\end{array}$ & $\begin{array}{l}\text { Porosity } \\
(\%)\end{array}$ \\
\hline 0 & $0.09 \pm 0.01$ & $1.08 \pm 0.03$ & 91.7 \\
10 & $0.10 \pm 0.02$ & $1.25 \pm 0.02$ & 92.0 \\
20 & $0.12 \pm 0.03$ & $1.33 \pm 0.03$ & 91.0 \\
30 & $0.17 \pm 0.02$ & $1.46 \pm 0.06$ & 88.4 \\
\hline
\end{tabular}

The data were representative of three samples and expressed as mean $\pm \mathrm{SD}(n=3)$.

The mechanical properties of the PLLA/BGC nanocomposites were evaluated by compressive measurements. The relationship between compressive properties and BGC 
content is summarized in Fig. 3. The compressive strength of composite increased from 0.27 to $0.35 \mathrm{MPa}$ while the compressive modulus increased from 5.5 to $8 \mathrm{MPa}$ as the BGC content increased from 0 to $30 \mathrm{wt} . \%$. This provides evidence that addition of $\mathrm{BGC}$ nanoparticles can effectively improve the mechanical properties of the PLLA porous scaffold. The enhancement of the mechanical performance due to the introduction of inorganic nanoparticles in composites has been intensively discussed in previous works $[23,47]$.

\subsection{In vitro bioactivity tests}

In order to analyze the osteoconductive character of the materials, and their potential for use in bone tissue engineering, bioactivity tests in SBF were performed on the PLLA/BGC nanocomposite scaffolds. Fig. 4 shows the morphology of porous PLLA and PLLA/BGC scaffolds after soaking in SBF for different periods. The composites with different BGC contents exhibit different bioactivities in SBF. For plain PLLA foam, some publications have

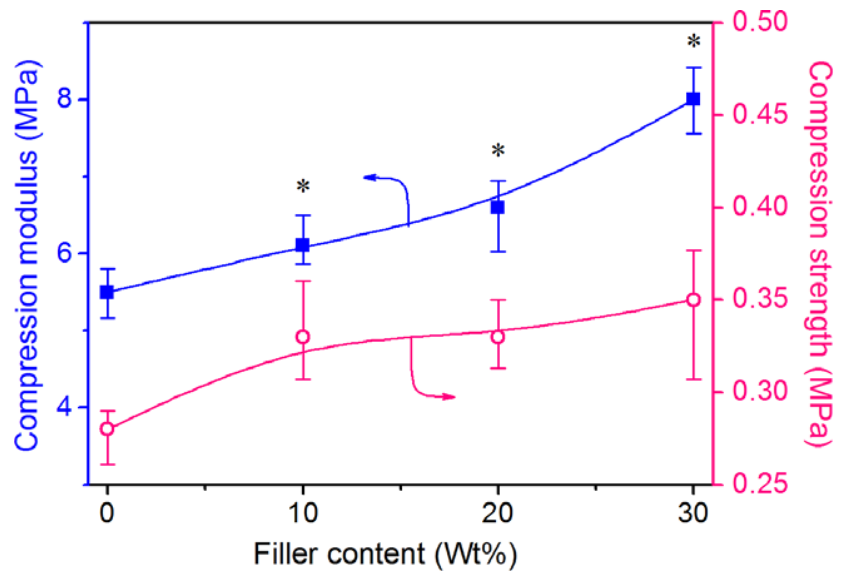

Fig. 3. Dependency of compressive strength and compressive modulus on the filler content in the porous nanocomposites. ${ }^{*} P<0.05$ : values were significantly different from the control PLLA group.

reported that porous PLLA scaffolds could induce the development of bone-like HA after soaking in SBF $[12,48,49]$. However, in this study, no apatite was formed
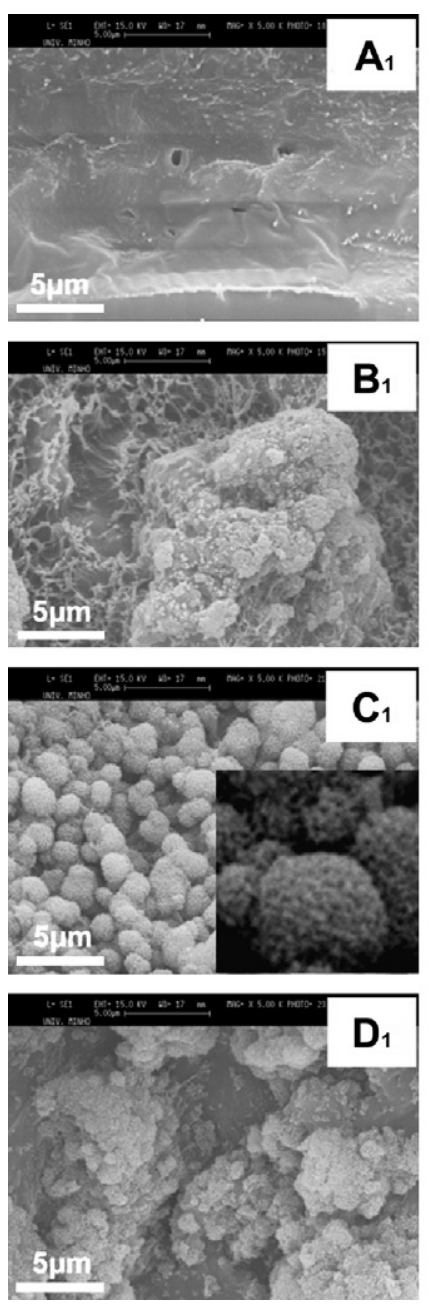
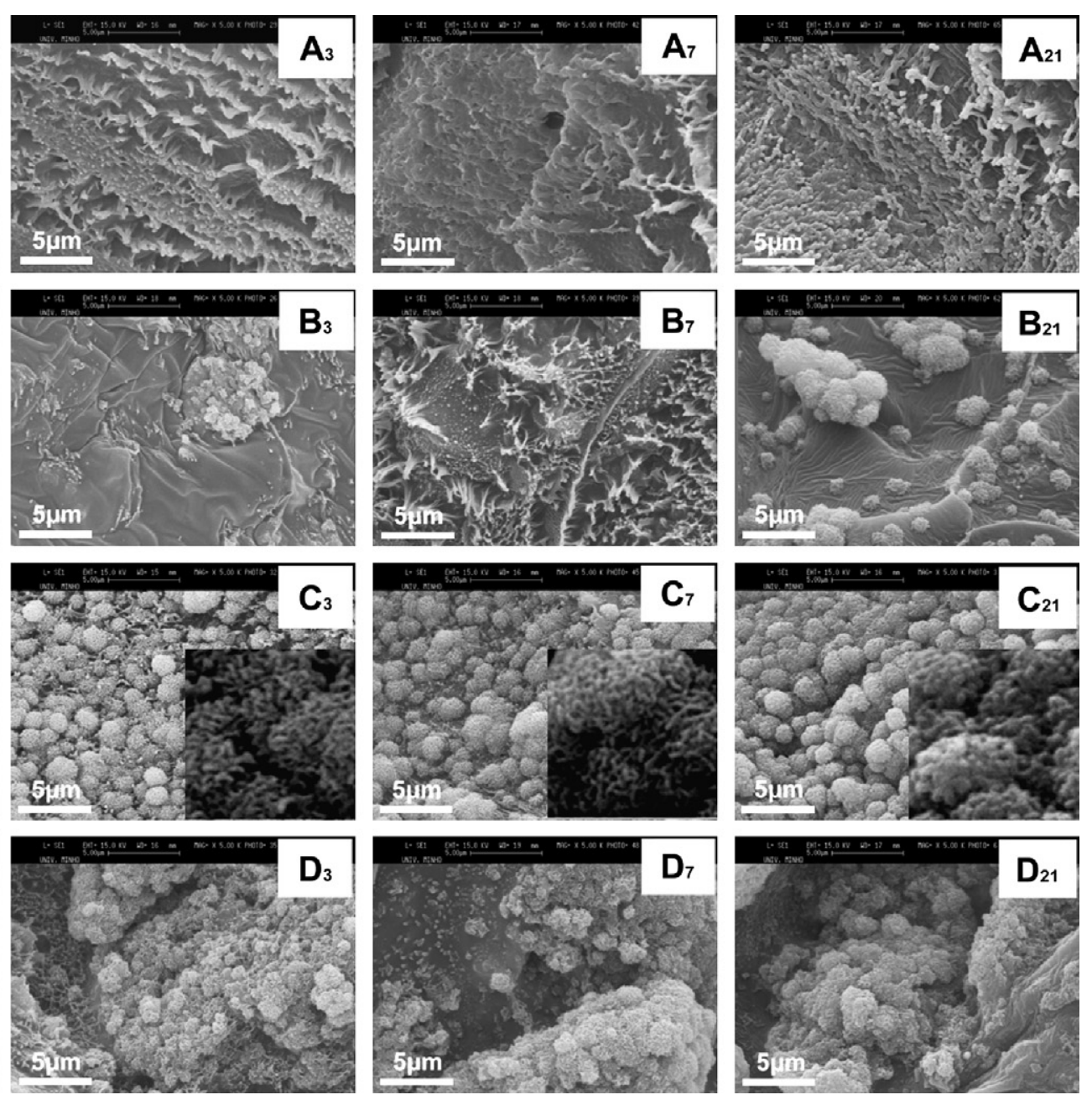

Fig. 4. Morphology of the porous PLLA/BGC composites with different contents of BGC particles after immersion in SBF for different periods, observed by SEM: (A) $0 \mathrm{wt} . \%$, (B) $10 \mathrm{wt} . \%$, (C) $20 \mathrm{wt} . \%$ and (D) $30 \mathrm{wt} . \%$. The subscripts indicate the incubation time in SBF (days). The images inserted in the C series are the high-magnification pictures of apatite clusters formed on the surface of PLLA/(20 wt.\%)BGC composites after different soaking times. 
on the surface of neat PLLA material after soaking in $1 \times \mathrm{SBF}$ as shown in Fig. 4A series. The result seems to indicate that less apatite tends to precipitate on the surface and in the interior of the PLLA scaffold. In this context it was suggested that the surface features of PLLA/Bioglass ${ }^{\circledR}$ particles could be changed, for example, by grafting a thermo-responsive polymer [50]; this produced smart materials that could induce calcification, or not, depending on the environmental temperature. For the $10 \mathrm{wt} . \%$ BGC content formulation, no apparent changes occurred on the surface of the composite scaffolds after soaking in SBF for 7 days (Fig. $4 \mathrm{~B}_{7}$ ). After 21 days of incubation, some cauliflower-like apatite clusters were formed on the surface of composite. For $20 \mathrm{wt} . \%$ BGC content, the biomineralization ability of the composite was greatly enhanced. After 1 day of incubation, the apatite clusters covered almost the entire surface of the scaffolds (Fig. $4 \mathrm{C}_{1}$ ). The profile of particles was clear, and elongated with increasing immersion time as shown in the high-magnification morphology of Fig. 4C series. This variation in particle shape was generally attributed to the tendency of HA to grow along the $c$-axis direction [51]. For PLLA/(30 wt.\%)BGC composite, after 1 day of incubation, nucleation and growth of apatite occurred on the exposed surface of the scaffold. However, the apatite clusters did not cover the entire surface of the composite. The results suggest that formation of bone-like apatite on PLLA/(30 wt.\%)BGC composite is delayed as compared with PLLA/ (20 wt.\%)BGC composite. This could be attributed to the overloading of $\mathrm{BGC}$ in the composite. The formulation with higher BGC content could result in more exposed BGC surface, but excessive exposed surface could decrease the development rate of apatite in SBF [12,52].

The results obtained by SEM were confirmed by EDX analysis as shown in Fig. 5. No obvious changes can be detected in the EDX curves for neat PLLA foam before and after soaking in SBF as shown in Fig. $4 \mathrm{~A}_{1}-\mathrm{A}_{21}$. EDX curves for the composites with different $\mathrm{BGC}$ contents show the presence of silicon $(\mathrm{Si})$, calcium $(\mathrm{Ca})$ and phosphorus $(\mathrm{P})$, and their relative quantity on the surface of the materials (Fig. 5B-D). As shown in Fig. 5B and $\mathrm{D}$, the ratio of $\mathrm{Si}, \mathrm{Ca}$ and $\mathrm{P}$ gradually changes with incubation time for PLLA/(10 wt.\%)BGC and PLLA/ (30 wt.\%)BGC composite. However, a significant variation in the intensity of $\mathrm{Si}, \mathrm{P}$ and $\mathrm{Ca}$ can be observed for the EDX data of the PLLA/(20 wt.\%)BGC scaffold (Fig. 5C). In this case, it can be seen that after soaking in SBF, the concentrations of $\mathrm{Ca}$ and $\mathrm{P}$ significantly increase, accompanied by a decrease in the concentration of $\mathrm{Si}$, which strengthens the indication of an extended development of apatite. From the result of EDX analysis, it can be concluded that the mineralization ability of the PLLA/ (20 wt.\%)BGC composite was superior to the other two formulations, which is in agreement with the SEM observations.

Fig. 6 shows XRD patterns of PLLA/(20 wt.\%)BGC nanocomposites after soaking in SBF for different periods.
After 1 day of incubation, the typical crystalline diffraction pattern of apatite can be observed with an evident peak at $2 \theta=26^{\circ}$ and $2 \theta=32^{\circ}$, which further intensified with increasing incubation time.

In addition, it could be seen that the PLLA matrix is in the amorphous state in the porous composites prepared by thermally induced phase-separation method. When the temperature was lowered to the upper critical solution temperature (UCST) of PLLA-dioxane solution, the homogeneous PLLA-dioxane solution separates into bicontinuous phases of PLLA and dioxane solvent to form an interpenetrating network structure. In this stage, the PLLA phase still contains a small quantity of dioxane solvent, whereas the dioxane phase also includes some PLLA solute. As the temperature is lowered further down to $-80^{\circ} \mathrm{C}$, both of these phases would be deep frozen. Hence, during the sublimation process of dioxane at $-80^{\circ} \mathrm{C}$, PLLA molecular chains were frozen in the solvent crystal lattice, preventing conformational mobility towards crystallization.

The FTIR spectrum of HA formed on the surface of PLLA/BGC composite is illustrated in Fig. 7a. The sample powder was scratched and collected from the surface of the PLLA/(20 wt.\%)BGC composite after soaking in SBF for 21 days. The spectrum of the particle is very similar to that of HA synthesized by coprecipitation method without calcination. Double peaks at 1450 and $1415 \mathrm{~cm}^{-1}$ indicate that the macroparticles formed on the surface of the composite correspond to carbonated apatite. The peak at 1760 (Fig. 7a) can be attributed to the vibration band of the carbonyl group of PLLA, which was scratched from the surface of PLLA/BGC composite together with the HA particles during the preparation of the FTIR sample.

\subsection{In vitro degradation}

In order to study the effect of BGC content on the degradability of the PLLA/BGC nanocomposite scaffolds, in vitro degradability tests were carried out in PBS $(\mathrm{pH}$ 7.4) at $37^{\circ} \mathrm{C}$. The degradation process was monitored by water uptake, weight loss and $\mathrm{pH}$ variation in the PBS medium. Fig. 8 shows the water uptake of the PLLA/BGC composites with different $\mathrm{BGC}$ content. It can be observed that after 1 day of immersion, compared with PLLA porous scaffold, the water content of all the PLLA/BGC composites increased with the introduction of BGC nanoparticles, which have a hydrophilic character. This result is consistent with our previous findings [42]. A mass increase of $600 \%$ is observed for pure PLLA foam, while for PLLA/BGC composites, this increase ranges from $650 \%$ to $800 \%$. PLLA/ (10 wt.\%)BGC composite exhibits the highest water absorption rate throughout the whole incubation period. The water uptake ability of the nanocomposite gradually decreases with further increase of filler loading due to the decrease in porosity at high filler contents. This result agrees with the results of the porosity analysis (Table 1).

The weight loss for the different porous PLLA/BGC scaffolds is shown in Fig. 9. The weight loss for the 

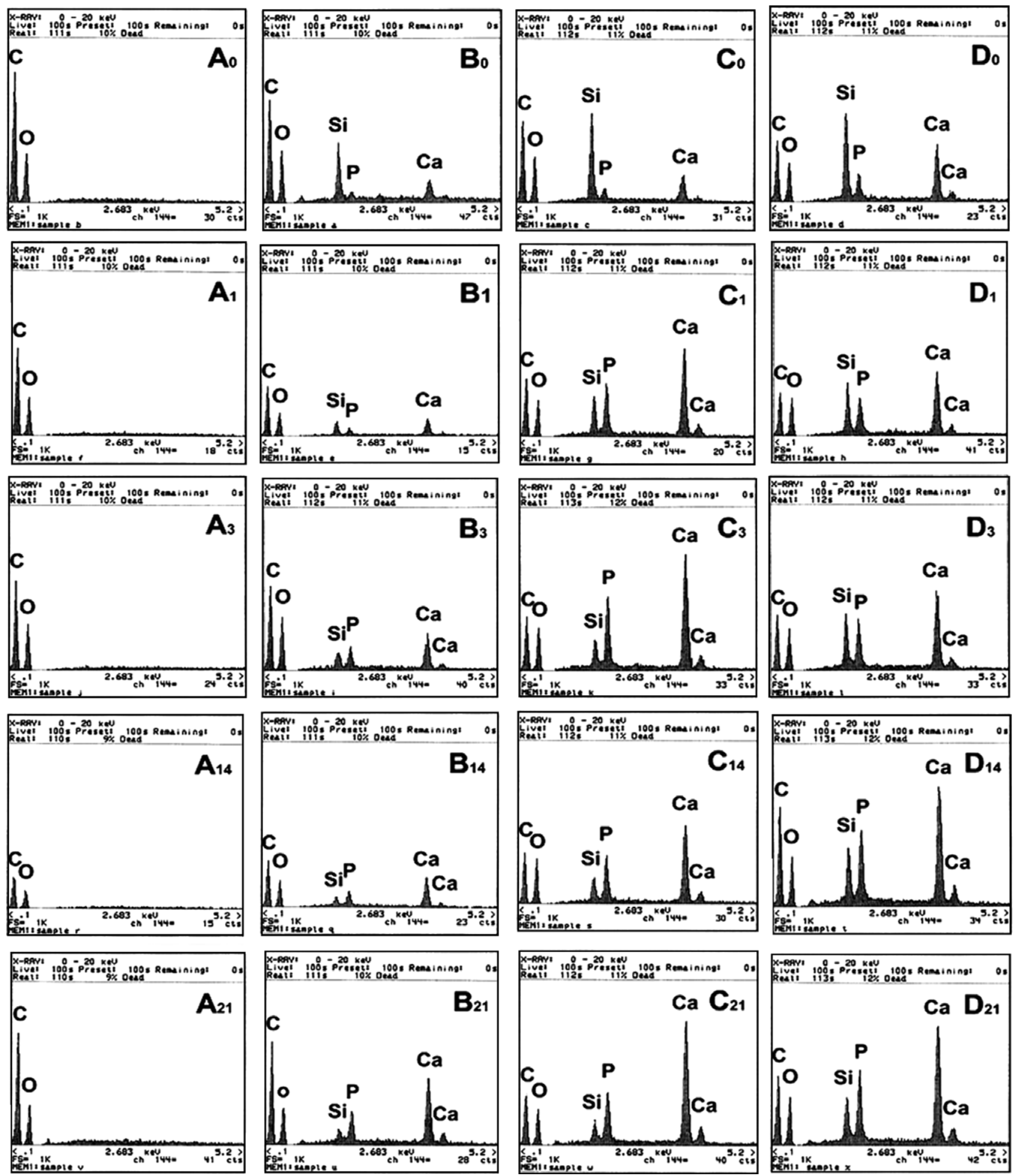

Fig. 5. EDX curves for porous PLLA/BGC composites with different contents of BGC particles after immersing in SBF for different periods: (A) 0 wt. $\%$, (B) $10 \mathrm{wt} . \%$, (C) $20 \mathrm{wt} . \%$ and (D) $30 \mathrm{wt} . \%$. The subscripts indicate the incubation time in SBF (days).

PLLA/BGC composites is slightly higher than for the plain PLLA foam, indicating a preferential dissolution of the inorganic component. After 30 days of incubation the PLLA/(30 wt. \%)BGC composites lost about $8 \%$ of their initial mass, which is slightly higher than loss in the other two composites.
$\mathrm{pH}$ variation of PBS media with different incubation times is presented in Fig. 10. Acidic groups resulting from the degradation of PLLA could decrease the $\mathrm{pH}$ value of medium, while the dissolution of the BGC nanoparticles could alkalize the medium. Therefore, the $\mathrm{pH}$ of the medium should depend on both the degradation rate of PLLA 


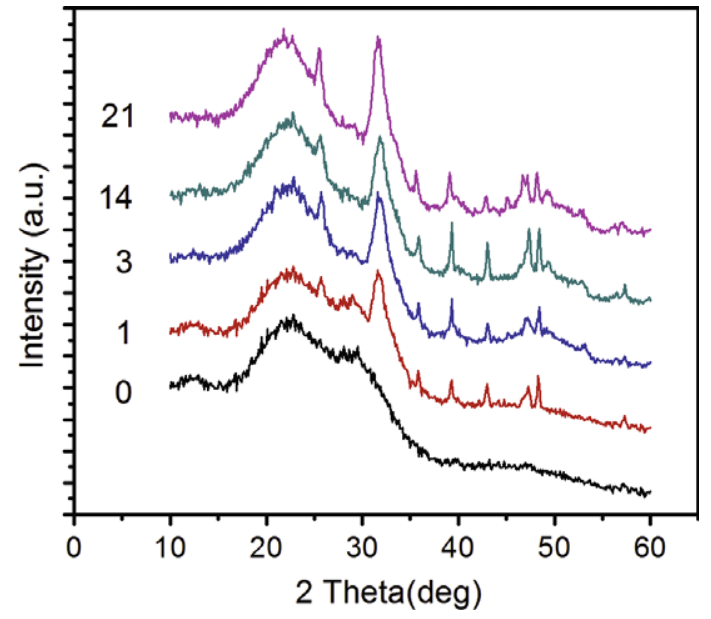

Fig. 6. XRD patterns of the PLLA/(20 wt. $\%)$ BGC composite after soaking in SBF for different periods (days).

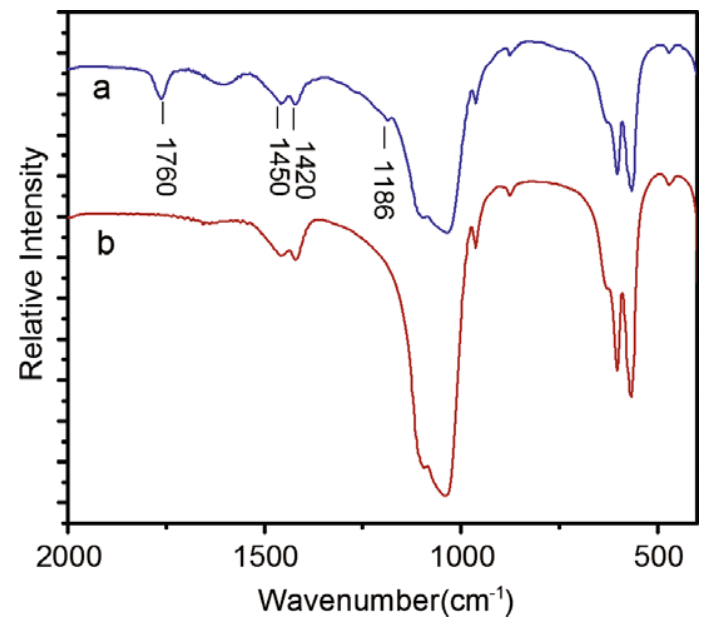

Fig. 7. FTIR spectra for: (a) the powder scratched from the surface of the PLLA/(20 wt.\%)BGC scaffold after soaking in SBF for 21 days and (b) $\mathrm{HA}$ synthesized by coprecipitation method with $\mathrm{Ca}(\mathrm{OH})_{2}$ and $\mathrm{H}_{3} \mathrm{PO}_{4}$ at $60^{\circ} \mathrm{C}$, presented as a reference.

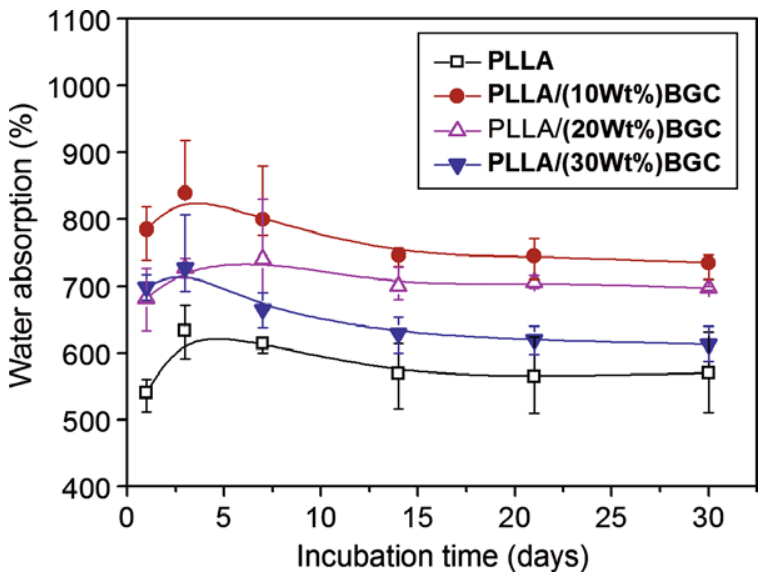

Fig. 8. Water uptake vs. incubation time in PBS for porous PLLA/BGC composites with different BGC contents: (a) $0 \mathrm{wt} . \%$, (b) $10 \mathrm{wt} . \%$, (c) $20 \mathrm{wt} . \%$ and (d) $30 \mathrm{wt} . \%$.

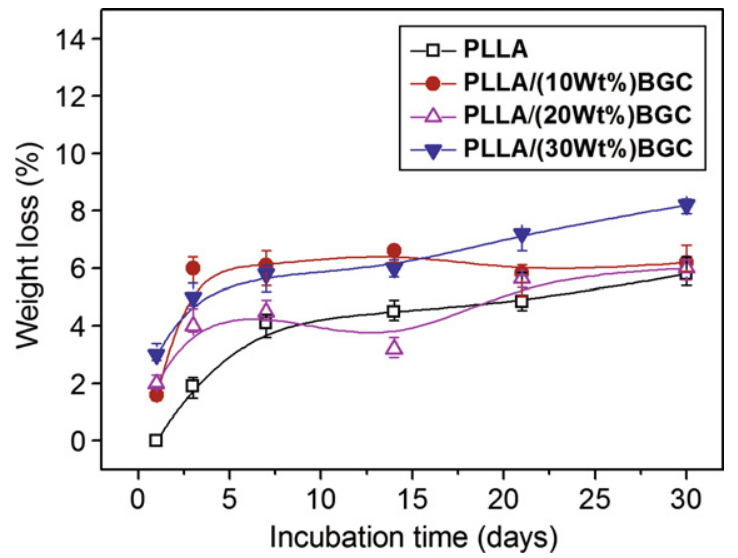

Fig. 9. Weight loss vs. incubation time in PBS for porous PLLA/BGC composites with different BGC contents: (a) 0 wt.\%, (b) $10 \mathrm{wt. \%}$, (c) 20 wt. $\%$ and (d) 30 wt. $\%$.

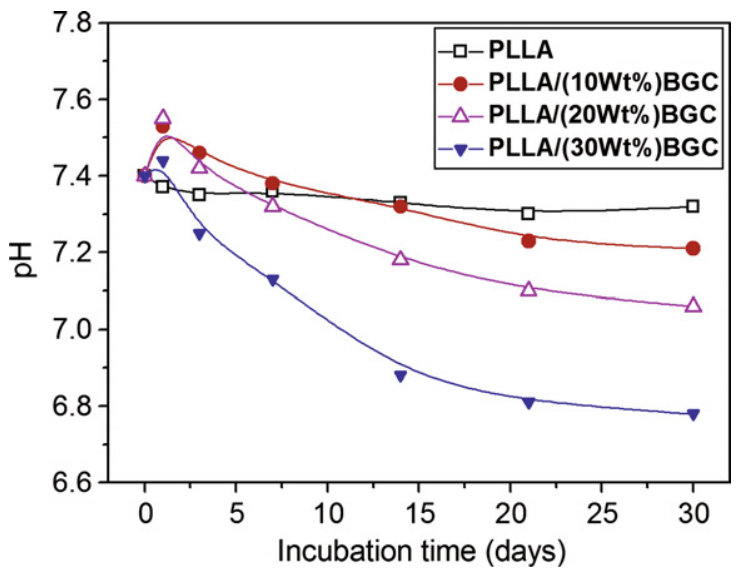

Fig. 10. Change in $\mathrm{pH}$ in PBS medium vs. incubation time for porous PLLA/BGC composites with different BGC contents: (a) 0 wt.\%, (b) 10 wt. $\%$, (c) 20 wt. $\%$ and (d) 30 wt. $\%$.

matrix and the dissolution profile of the BGC nanoparticles. As shown in Fig. 10, a slight decrease in $\mathrm{pH}$ occurs at the initial incubation stage for the PLLA foam. After 3 days of incubation, the $\mathrm{pH}$ value of the medium of neat PLLA foam reaches a plateau value at around 7.3. The $\mathrm{pH}$ evolution of the PLLA/BGC composites with 10, 20, and $30 \mathrm{wt} . \%$ BGC content exhibits a different trend, slightly increasing in the first day of incubation and then decreasing gradually to around 7.2, 7.1 and 6.8 after 4 weeks of incubation, respectively. Several publications [2,53-55] have reported that bioactive ceramic filler could delay the degradation of the composite scaffolds by the neutralizing effect of the alkaline ions released from the bioactive ceramic particle in culturing medium. However, in this study, during 4 weeks of incubation, it was found that overloading BGC nanoparticles could accelerate the degradation of PLLA/BGC composites. Hydrophilic BGC nanoparticles with a large specific area could facilitate the infiltration of water inside the composite structure, which might result in an enhancement of degradation of the PLLA matrix in 
both the surface and the interior of the composite, releasing more acidic degradation products into the medium $[25,55]$.

\section{Conclusion}

PLLA/BGC nanocomposite scaffolds with different BGC contents were obtained via a thermally induced phase-separation method, in which dioxane was used as the solvent for PLLA. Introduction of 10 and $20 \mathrm{wt} . \%$ BGC nanoparticles in PLLA did not remarkably alter the morphology and porosity of the scaffolds. The apparent density of the materials increased with increasing BGC content. The porosity of the scaffolds containing $30 \mathrm{wt} . \%$ BGC decreased remarkably as compared with both PLLA/(10 wt.\%)BGC and PLLA/(20 wt.\%)BGC formulations. Mechanical properties could be improved by adding the developed BGC nanoparticles in the PLLA matrix. In vitro mineralization tests showed that of the three composites and neat PLLA foam, the PLLA/(20 wt.\%)BGC composite exhibits the best bioactivity features. Biodegradation results indicated that the inclusion of BGC nanoparticles could increase the water uptake of PLLA scaffolds, especially at a lower BGC loading, and greatly affect the degradation rate of the PLLA matrix.

\section{Acknowledgements}

This work was financially supported by FCT Grant for postdoctoral research (SFRH/BPD/25828/2005), and by the Projects POCTI/FIS/61621/2004 and PTDC/QUI/ $69263 / 2006$. The authors also would like to acknowledge Dr. Aixue Liu, Changchun Institute of Applied Chemistry, for his help in characterization of composite material.

\section{References}

[1] Langer R, Vacanti J. Tissue engineering. Science 1993;260:920-6.

[2] Maquet V, Boccaccini AR, Pravata L, Notingher I, Jérôme R. Porous poly(a-hydroxyacid)/bioglass composite scaffolds for bone tissue engineering. I: Preparation and in vitro characterization. Biomaterials 2004;25:4185-94.

[3] Mano JF, Sousa RA, Boesel LF, Neves NM, Reis RL. Bioinert, biodegradable and injectable polymeric matrix composites for hard tissue replacement: state of the art and recent developments. Compos Sci Technol 2004;64:789-817.

[4] Chouzouri G, Xanthos M. In vitro bioactivity and degradation of polycaprolactone composites containing silicate fillers. Acta Biomater 2007;3:745-56.

[5] Griffith LG. Emerging design principles in biomaterials and scaffolds for tissue engineering. Ann NY Acad Sci 2002;961:83-95.

[6] Karageorgiou V, Kaplan D. Porosity of 3D biomaterial scaffolds and osteogenesis. Biomaterials 2005;26:5474-91.

[7] Devin JE, Attawia M, Laurencin CT. Three-dimensional degradable porous polymer-ceramic matrices for use in bone repair. J Biomater Sci: Polym Edn 1996;7:661-9.

[8] Marra KG, Szer JW, Kumta PN, DiMilla PA, Weiss LE. In vitro analysis of biodegradable polymer blend/hydroxyapatite composites for bone tissue engineering. J Biomed Mater Res 1999;47:324-35.

[9] Zhang R, Ma PX. Poly(a-hydroxyl acids)/hydroxyapatite porous composites for bone-tissue engineering. I. Preparation and morphology. J Biomed Mater Res 1999;44:446-55.
[10] Maquet V, Boccaccini AR, Pravata L, Notingher I, Jérôme R. Preparation, characterization, and in vitro degradation of bioresorbable and bioactive composites based on bioglass-filled polylactide foams. J Biomed Mater Res A 2003;66:335-46.

[11] Lee SJ, Park YJ, Park SN, Lee YM, Seol YJ, Ku Y, et al. Molded porous poly(L-lactide) membranes for guided bone regeneration with enhanced effects by controlled growth factor release. J Biomed Mater Res 2001;55:295-303.

[12] Zhang K, Wang Y, Hillmyer MA, Francis LF. Processing and properties of porous poly(L-lactide)/bioactive glass composites. Biomaterials 2004;25:2489-500.

[13] Korventausta J, Jokinen M, Rosling A, Peltola T, Yli-Urpo A. Calcium phosphate formation and ion dissolution rates from silica gel-PDLLA composites. Biomaterials 2003;24:5173-518.

[14] Boccaccini AR, Blaker JJ, Maquet V, Chung W, Jérôme R, Nazhat SN. Poly(D,L-lactide) (PDLLA) foams with $\mathrm{TiO}_{2}$ nanoparticles and PDLLA/ $/ \mathrm{TiO}_{2}$-Bioglass ${ }^{\circledR}$ foam composites for tissue engineering scaffolds. J Mater Sci 2006;41:3999-4008.

[15] Blaker JJ, Maquet V, Jérôme R, Boccaccini AR, Nazhat SN. Mechanically anisotropic PDLLA/bioglass composite foams as scaffolds for bone tissue engineering. Acta Biomater 2005;1:643-52.

[16] Blaker JJ, Gough JE, Maquet V, Notingher I, Boccaccini AR. In vitro evaluation of novel bioactive composites based on bioglass-filled polylactide foams for bone tissue engineering scaffolds. J Biomed Mater Res A 2003;67:1401-11.

[17] Roether JA, Boccaccini AR, Hench LL, Maquet V, Gautier S, Jérôme R. Development and in vitro characterisation of novel bioresorbable and bioactive composite materials based on polylactide foams and bioglass $(\mathrm{R})$ for tissue engineering applications. Biomaterials 2002;23:3871-8.

[18] Verrier S, Blaker JJ, Maquet V, Hench LL, Boccaccini AR. PDLLA/ bioglass( $\mathrm{R})$ composites for soft-tissue and hard-tissue engineering: an in vitro cell biology assessment. Biomaterials 2004;25:3013-21.

[19] Kim HW, Knowles JC, Kim HE. Hydroxyapatite/poly(e-caprolactone) composite coatings on hydroxyapatite porous bone scaffold for drug delivery. Biomaterials 2004;25:1279-87.

[20] Choi D, Marra KG, Kumta PN. Chemical synthesis of hydroxyapatite/ poly(e-caprolactone) composites. Mater Res Bull 2004;39:417-32.

[21] Day RM, Boccaccini AR, Shurey S, Roether JA, Forbes A, Hench LL, et al. Assessment of polyglycolic acid mesh and bioactive glass for soft-tissue engineering scaffolds. Biomaterials 2004;25:5857-66.

[22] Day RM, Maquet V, Boccaccini AR, Jérôme R, Forbes A. In vitro and in vivo analysis of macroporous biodegradable poly(D,L-lactideco-glycolide) scaffolds containing bioactive glass. J Biomed Mater Res A 2005;75:778-87.

[23] Hong Z, Zhang P, Liu A, Chen L, Chen X, Jing X. Composites of poly(lactide-co-glycolide) and the surface modified carbonated hydroxyapatite nano-particles. J Biomed Mater Res A 2007;81(3):515-22.

[24] Jaakkola T, Tirri T, Närhi T, Jokinen M, Seppälä J. In vitro Ca-P precipitation on biodegradable thermoplastic composite of poly(ecaprolactone-co-dl-lactide) and bioactive glass (S53P4). Biomaterials 2004;25:575-81.

[25] Rich J, Jaakkola T, Tirri T, Närhi T, Yli-Urpo A, Seppälä J. In vitro evaluation of poly(e-caprolactone-co-DL-lactide)/bioactive glass composites. Biomaterials 2002;23:2143-50.

[26] Zhao L, Chang J. Preparation and characterization of macroporous chitosan/wollastonite composite scaffolds for tissue engineering. J Mater Sci: Mater Med 2004;15:625-9.

[27] Oliveira JM, Rodrigues MT, Silva SS, Malafaya PB, Gomes ME, Viegas CA, et al. Novel hydroxyapatite/chitosan bilayered scaffold for osteochondral tissue-engineering applications: scaffold design and its performance when seeded with goat bone marrow stromal cells. Biomaterials 2006;27:6123-37.

[28] Silva GA, Coutinho OP, Ducheyne P, Shapiro IM, Reis RL. The effect of starch and starch-bioactive glass composite microparticles on the adhesion and expression of the osteoblastic phenotype of a bone cell line. Biomaterials 2007;28:326-34. 
[29] Ghosh S, Viana JC, Reis RL, Mano JF. Bi-layered constructs based on poly(L-lactic acid) and starch for tissue engineering of osteochondral defects. Mater Sci Eng 2008;28C:80-6.

[30] Kokubo T, Kim HM, Kawashita M. Novel bioactive materials with different mechanical properties. Biomaterials 2003;24:2161-75.

[31] Hench LL. Ceramics glasses and glass-ceramics. In: Ratner BD, Hoffman AS, Schoen FJ, Lemons JE, editors. Biomaterials science: an introduction to materials in medicine. San Diego, CA: Academic Press; 1996. p. 84.

[32] Xynos ID, Hukkanen MVJ, Buttery LDK, Hench LL, Polak JM. Bioglass 45S5 stimulates osteoblast turnover and enhances bone formation in vitro: implications and applications for bone tissue engineering. Calcif Tissue Int 2000;67:321-9.

[33] Wheeler DL, Montfort MJ, McLoughlin SW. Differential healing response of bone adjacent to porous implants coated with hydroxyapatite and 45S5 bioactive glass. J Biomed Mater Res A 2001;55:603-12.

[34] Hench LL. Bioceramics. J Am Ceram Soc 1998;81:1705-28.

[35] Hench LL. Sol-gel materials for bioceramic applications. Curr Opin Solid State Mater Sci 1997;2:604-10.

[36] Gauthier O, Bouler JM, Aguado E, Pilet P, Daculsi G. Macroporous biphasic calcium phosphate ceramics: influence of macropore diameter and macroporosity percentage on bone ingrowth. Biomaterials 1998;19:133-9.

[37] Jiang G, Shi D. Coating of HA on porous alumina substrate through a thermal decomposition method. J Biomed Mater Res 1999;48:117-20.

[38] Shi D, Jiang G, Wen X. In vitro bioactive behavior of hydroxylapatite-coated porous $\mathrm{Al}_{2} \mathrm{O}_{3}$. J Biomed Mater Res 2000;53:457-66.

[39] Rezwan K, Chen Q, Blaker JJ, Boccaccini AR. Biodegradable and bioactive porous polymer/inorganic composite scaffolds for bone tissue engineering. Biomaterials 2006;27:3413-31.

[40] Kothapalli CR, Shaw MT, Wei M. Biodegradable HA-PLA 3D porous scaffolds: effect of nano-sized filler content on scaffold properties. Acta Biomater 2005;1:653-62.

[41] Roco MC. Nanoparticles and nanotechnology research. J Nanopart Res 1999;1:1-6.

[42] Hong Z, Reis RL, Mano JF. Preparation and in vitro characterization of novel bioactive glass ceramic nanoparticles. J Biomed Mater Res $\mathrm{A}$, in press.
[43] Hong Z, Liu A, Chen L, Chen X, Jing X. Preparation of bioactive glass ceramic nanoparticles by combination of sol-gel and coprecipitation method, submitted for publication.

[44] Kokubo T, Takadama H. How useful is SBF in predicting in vivo bone bioactivity? Biomaterials 2006;27(15):2907-15.

[45] Leonor IB, Sousa RA, Cunha AM, Reis RL, Zhong ZP, Greenspan D. Novel starch thermoplastic/Bioglass ${ }^{\circledR}$ composites: mechanical properties, degradation behavior and in-vitro bioactivity. J Mater Sci: Mater Med 2002;13:939-45.

[46] Schugens C, Maquet V, Grandfils C, Jérôme R, Teyssié P. Biodegradable and macroporous polylactide implants for cell transplantation: 1. Preparation of macroporous polylactide supports by solid-liquid phase separation. Polymer 1996;37:1027-38.

[47] Hong Z, Zhang P, He C, Qiu X, Liu A, Chen L, et al. Nanocomposite of poly(L-lactide) and surface grafted hydroxyapatite: mechanical properties and biocompatibility. Biomaterials 2005;26:6296-304.

[48] Zhang R, Ma PX. Porous poly(L-lactic acid)/apatite composites created by biomimetic process. J Biomed Mater Res 1999;45:285-93.

[49] Murphy WL, Mooney DJ. Bioinspired growth of crystalline carbonate apatite on biodegradable polymer substrata. J Am Chem Soc 2002;124:1910-7.

[50] Shi J, Alves NM, Mano JF. Thermally responsive biomineralization on biodegradable substrates. Adv Funct Mater 2007;17:3312-8.

[51] Li H, Huang W, Zhang Y, Zhong M. Biomimetic synthesis of enamellike hydroxyapatite on self-assembled monolayers. Mater Sci Eng C 2007;27:756-61.

[52] Yan H, Zhang K, Blandford CF, Francis LF, Stein A. In vitro hydroxycarbonate apatite mineralization of $\mathrm{CaO}-\mathrm{SiO}_{2}$ sol-gel glasses with a 3-dimensionally ordered macroporous Structure. Chem Mater 2001;13:1374-82.

[53] Li H, Chang J. pH-Compensation effect of bioactive inorganic fillers on the degradation of PLGA. Compos Sci Technol 2005;65:2226-32.

[54] Xu X, Chen X, Liu A, Hong Z, Jing X. Electrospun poly(L-lactide)grafted hydroxyapatite/poly(L-lactide) nanocomposite fibers. Eur Polym J 2007;43:3187-96.

[55] Yang F, Cui W, Xiong Z, Liu L, Bei J, Wang S. Poly(L,L-lactide-coglycolide)/tricalcium phosphate composite scaffold and its various changes during degradation in vitro. Polym Degrad Stab 2006;91:3065-73. 